\title{
Políticas Públicas de Inclusão Digital: desafios educacionais na sociedade contemporânea
}

Silvana Tomazi Camozzato ${ }^{1}$ Miguel Angelo Perondi ${ }^{2}$ Nilvania Aparecida de Mello $^{3}$

\begin{abstract}
Resumo
Este artigo tem como principal objetivo analisar as Políticas Públicas de Inclusão Digital dirigidas ao sistema educacional, na perspectiva de atender às novas tecnologias direcionadas para a educação, presentes na sociedade contemporânea. Através desta análise, busca-se caracterizar os desafios enfrentados pela escola, na inclusão da tecnologia digital como ferramenta pedagógica dos professores, identificar as Políticas Públicas de Inclusão Digital e observar como são desenvolvidas no ambiente escolar, como também refletir sobre o papel das tecnologias na sociedade contemporânea no que se refere à formação do cidadão. $O$ trabalho foi desenvolvido com base em autores cujos estudos estão relacionados ao tema e em dados e informações obtidos pelo Ministério da Educação e Cultura (MEC). Em síntese, este estudo destaca as necessidades e desafios das políticas públicas voltadas para a globalização e igualdade de condições de acesso às TIC's.
\end{abstract}

Palavras-chave: Políticas Públicas. Inclusão Digital. Educação. Sociedade.

\begin{abstract}
This article is meant to examine public policies directed to Digital Inclusion educational system with a view to cater to new technologies targeted for education in today's society. Through this analysis, we seek to characterize the challenges faced by the school in the inclusion of digital technology as a pedagogical tool for teachers, identify the public policy of digital inclusion and how they are developed in the school environment, but also reflect on the role of technology in modern society related to the formation of the citizen. The study was developed based on the studies of authors related to the subject and the data and information obtained by the Ministry of Education and Culture (MEC). In summary, this study highlights the needs and challenges of Brazilian society, as well as education with public policies for globalization and equal conditions of access to ICT.
\end{abstract}

Keywords: Public Policy. Digital Inclusion. Education. Society.

\footnotetext{
${ }^{1}$ Mestranda do Programa de Pós-Graduação em Desenvolvimento Regional pela Universidade Tecnológica Federal do Paraná (UTFPR) - Pato Branco/PR. silvanatutoria@hotmail.com

2 Professor Doutor. Docente do Programa de Pós-Graduação em Desenvolvimento Regional (UTFPR). miguelangeloperondi@gmail.com

3 Professora Doutora. Docente do Programa de Pós-Graduação em Desenvolvimento Regional (UTFPR).nilvania@utfpr.edu.br
} 


\section{Introdução}

A sociedade contemporânea passa por transformações políticas, econômicas e sociais, que hoje ocorrem de modo rápido e intenso. Nessa dinâmica, os atores tentam adequar-se às novas exigências sociais, através de estudos e capacitações constantes, para dar conta do emaranhado de informações e dominar o conhecimento. Este, por sua vez, intensificado na chamada "sociedade da informação" ou "era do conhecimento". De acordo com Bernheim e Chauí (2008), uma das características da sociedade contemporânea é o papel do conhecimento no processo de produção, apontando para um novo paradigma econômico.

As Tecnologias de Informação e Comunicação (TIC's) promoveram transformações no cotidiano das pessoas, mudando seus hábitos, cultura e trabalho. Para que essas mudanças ocorressem de forma linear, o governo criou políticas públicas de inclusão digital, no intuito de oferecer-lhes condições de acessibilidade aos meios digitais. Neste cenário, o foco nas TIC's exige políticas públicas e programas do Estado brasileiro, possibilitando às pessoas o acesso a essas tecnologias num processo de universalização, democratização e inclusão digital.

No contexto das políticas públicas de inclusão digital, encontra-se a educação, que é um veículo de tratamento das informações. Dentro da escola, as TIC's podem ser desenvolvidas pelos professores como ferramenta pedagógica na construção do conhecimento dos alunos, mas as ações nem sempre são compreendidas pelo professor que irá executá-las. Dessa forma, torna-se necessária uma análise dos desafios enfrentados pelos professores na aplicação das tecnologias digitais.

Diante deste cenário, busca-se identificar e conhecer as políticas públicas de inclusão digital que permeiam a educação, no sentido de envolver os atores na utilização do espaço público como local da democratização do acesso aos recursos tecnológicos.

Atualmente, a educação modificou o seu papel de detentora do saber para mediadora do conhecimento, tendo que formar cidadãos capazes de se adaptar a situações complexas e resolver problemas. Um desafio complexo, mas exigido pela nova sociedade, que requer pessoas que dominem as tecnologias por meio do conhecimento. Num mundo capitalista, dominado pelas tecnologias para o mercado, não se sabe mais que tipo de cidadão formar.

Em virtude dessas ideias apresentadas, justifica-se a realização deste estudo como uma forma de refletir sobre as políticas públicas de inclusão digital impostas à educação, frente a uma modernidade tecnológica que, de maneira sorrateira, adentra as escolas, as quais não estão dando conta da expansão das TIC's na sociedade contemporânea, na qual os alunos (con)vivem.

Para realizar a reflexão deste tema, serão abordadas obras de autores, materiais e informações do Ministério de Educação e Cultura (MEC), todos relacionados ao contexto, subsidiando a produção deste artigo.

Num primeiro momento, serão conceituadas as políticas públicas por meio de uma abordagem geral; depois, sobre as políticas públicas de inclusão digital e sua configuração na área educacional.

Em seguida, serão apontados os desafios da inclusão digital na educação pelo 
viés da prática pedagógica do professor, e, por fim, será feita uma abordagem sobre a sociedade contemporânea nos moldes da "sociedade da informação".

\section{Breve comentário sobre políticas públicas}

Para estabelecer ordem, organização e regras, surgem as políticas públicas elaboradas pelo poder público, visando atender aos moldes sociais presentes no cotidiano das pessoas. No início, as políticas públicas aparecem como disciplina acadêmica, e, de acordo com Laswell (1958), análise de política pública é uma forma de conciliar conhecimento científico/acadêmico com a produção empírica dos governos, num viés de estabelecer comunicação entre cientistas sociais e grupos de interesse do governo.

Existem vários conceitos de políticas públicas, mas Lynn (1980) é quem mais se aproxima de um conceito que se adapta ao tema deste trabalho, colocando que as políticas públicas são um conjunto de ações do governo que irão produzir efeitos específicos. Outros autores apontam as políticas públicas como solução de problemas.

Frey (2000) ainda expõe sobre a Policy analysis, conceitos importantes para a compreensão de políticas públicas. Segundo o autor, cada conceito está ligado a três abordagens da ciência política, sendo elas as seguintes:

- Polity - ordem do sistema político - conteúdo da política;

- Politics - processos políticos de caráter conflituoso;

- Policy - configuração dos programas políticos. Tais abordagens, ora dependentes, ora independentes, mas entrelaçadas influenciam-se mutuamente. São definições para o entendimento de como ocorre o processo político.

De modo geral, as políticas públicas buscam atender aos interesses do governo, principalmente o regado pelo sistema capitalista, que dificulta o desenvolvimento humano, o qual, para Sen (2010), além de melhorar a qualidade de vida, influencia as habilidades produtivas das pessoas, e, portanto, o crescimento econômico.

Cabe ressaltar que as políticas públicas comungam com as políticas sociais, ou seja, cada política pública vai influenciar a vida social das pessoas, a repercussão de suas ações abrange várias áreas, daí o interesse de outros campos, como os relacionados à economia, sociologia, antropologia, geografia, de serem contemplados por elas.

Partindo da premissa de que o Brasil é um país em desenvolvimento, Sen (2010) enfatiza a importante necessidade de iniciativas de política pública na criação de oportunidades sociais, visto que, nos países ricos, as ações voltadas para a educação, saúde, reforma agrária possibilitaram o processo de expansão econômica da população. As bases que atendem a sociedade precisam ser dialogadas, com a participação ativa das pessoas, para construir a "espinha dorsal" que atenderá aos seus anseios e necessidades da sociedade.

Portanto, as políticas públicas encontram-se inseridas no contexto político, articuladas pelos interesses do momento, mas, ao mesmo tempo, regem a ordem de como devem ocorrer os fatos e também o esforço de oferecer a igualdade de direitos a todos os cidadãos. No entanto, hoje a sociedade não pode apenas esperar pelos serviços públicos, existem outros atores, como empresas e organizações não governamentais, que 
precisam fazer parte da estrutura e iniciar práticas de bem comum a todos.

\section{Políticas Públicas de Inclusão Digital}

Na sociedade contemporânea o capitalismo, a globalização e a difusão das tecnologias, que influenciam as pessoas em relação a uma gama de informações e ao consumismo. Com tantas mudanças, fazem-se necessários programas de governo que atendam essa demanda, para possibilitar às pessoas o acesso às tecnologias, com participação da sociedade e do governo na democratização da inclusão digital. Diante das modernidades sociais apresentadas, surge a necessidade da produção do conhecimento e da informação, para realizar o processo de difusão das ferramentas tecnológicas, com práticas embasadas em políticas públicas de difusão social.

Segundo Hobsbawm (1995), pesquisa e desenvolvimento tornaram-se fundamentais para o crescimento econômico; o processo de inovação passou a ser contínuo, e, com isso, o desenvolvimento científico e tecnológico necessita de planejamento e políticas governamentais para fundir e valorizar este processo, uma contrariedade com a era industrial, quando surgiu a máquina a vapor, e a energia gerava produtividade.

Atualmente, a produção e o acesso à tecnologia são fatores de desenvolvimento econômico e social nos locais onde se encontram. No caso do Brasil, o que mais se difunde é a rede de internet, principalmente nos domicílios, de acordo com o Centro de Estudos sobre as Tecnologias da Informação e da Comunicação (Cetic.br). Em 2012, 40\% dos domicílios brasileiros tinham acesso à internet. Isso significa que, além da expansão da rede através de políticas públicas de inclusão, também existe o aumento de consumo das tecnologias móveis para ter o acesso às informações.

\section{Quadro 1 - Locais de Inclusão Digital}

\begin{tabular}{|c|c|c|c|c|c|c|c|c|c|}
\hline \multicolumn{10}{|c|}{ Horizontal - Total } \\
\hline \multicolumn{10}{|c|}{ População Total } \\
\hline $\begin{array}{c}\text { Percentual } \\
(\%)\end{array}$ & $\begin{array}{l}\text { Faixa } \\
\text { Etária }\end{array}$ & $\begin{array}{l}\text { População } \\
\text { (contagem) }\end{array}$ & $\begin{array}{l}\text { Utilizou } \\
\text { a } \\
\text { Internet } \\
\text { em } \\
\text { algum } \\
\text { local }\end{array}$ & $\begin{array}{c}\text { Utilizou a } \\
\text { Internet em } \\
\text { seu domicílio } \\
\text { por acesso } \\
\text { discado }\end{array}$ & $\begin{array}{c}\text { Utilizou a } \\
\text { Internet em } \\
\text { seu domicílio } \\
\text { por banda } \\
\text { larga }\end{array}$ & $\begin{array}{l}\text { Utilizou a } \\
\text { Internet } \\
\text { em seu } \\
\text { trabalho }\end{array}$ & $\begin{array}{c}\text { Utilizou a } \\
\text { Internet em } \\
\text { estabelecimento } \\
\text { em que } \\
\text { frequentava } \\
\text { algum curso }\end{array}$ & $\begin{array}{l}\text { Utilizou a } \\
\text { Internet em } \\
\text { centro público } \\
\text { de acesso } \\
\text { gratuito ou } \\
\text { pago }\end{array}$ & $\begin{array}{c}\text { Utilizou a } \\
\text { Internet em } \\
\text { domicílio de } \\
\text { outros parentes, } \\
\text { amigos ou outro } \\
\text { local }\end{array}$ \\
\hline Total & Total & 186.440 .290 & 29,79 & 3,35 & 13,98 & 9,24 & 5,21 & 11,23 & 5,87 \\
\hline
\end{tabular}

Fonte: Néri (2012).

Nesse Quadro, foram colocados índices percentuais, para apontar o uso da internet e o local onde foi utilizada, demonstrando que a tecnologia móvel está mais próxima dos usuários, os quais, portanto, podem ter acesso às redes com maior facilidade e constância. Por isso é que as políticas públicas devem estar voltadas para o acesso livre da internet, ampliando as redes de conexão e garantindo a sua qualidade.

Conforme a Lei no 9472 de 1997 (BRASIL, 1997),

obrigações de universalização são as que objetivam possibilitar o acesso de qualquer pessoa ou instituição de interesse público a serviço de telecomunicação, independente de sua localização e condição sócio econômica, bem como as destinadas a permitir a utilização das telecomunicações em serviços essenciais de interesse público. 
Tabela 1 - Pessoas de 10 anos ou de mais idade que utilizaram a Internet, no período de referência dos últimos três meses, por Grandes Regiões, segundo os grupos de idade -2005

\begin{tabular}{lcccccc}
\hline Grupos de idade & Brasil & Norte & Nordeste & Sudeste & Sul & $\begin{array}{c}\text { Centro- } \\
\text { Oeste }\end{array}$ \\
\hline 10 a 14 anos & 4200290 & 181820 & 669538 & 2216173 & 797927 & 334832 \\
15 a 17 anos & 3605186 & 161566 & 607386 & 1896662 & 653505 & 286067 \\
18 ou 19 anos & 2330719 & 117160 & 424132 & 1187528 & 414251 & 187648 \\
20 a 24 anos & 5386456 & 249123 & 928484 & 2850421 & 931527 & 426901 \\
25 a 29 anos & 4198177 & 197593 & 668307 & 2250995 & 740918 & 340364 \\
30 a 39 anos & 5757389 & 247607 & 807706 & 3158002 & 1070306 & 473768 \\
40 a 49 anos & 4084462 & 147376 & 514443 & 2353074 & 773592 & 295977 \\
50 anos ou mais & 2537664 & 62666 & 292176 & 1570679 & 447074 & 165049 \\
\hline
\end{tabular}

Fonte: IBGE (2005).

Contudo, ainda existe uma disparidade de acesso aos benefícios para a população. O Brasil possui uma densidade demográfica e desigualdade de renda que dificultam a criação de políticas públicas para o coletivo. A tabela acima ilustra essa realidade, no ano de 2005, comparando as regiões, de acordo com a faixa etária da população, quanto ao acesso à internet.

Pode-se perceber que, no total da população, os grupos na faixa etária de 10 anos em diante tiveram um crescente uso da internet, porque utilizaram uma tecnologia móvel cujo acesso à rede poderia ocorrer em qualquer lugar. Já por região, verificou-se que, na região Norte e na Nordeste, as pessoas utilizaram a internet quase na mesma proporção. Há de se considerar, nesta tabela, o nível de instrução e de renda das pessoas pesquisadas.

Convém realçar que, em se tratando de igualdade do direito defendido aqui, ou seja, o de que todas as pessoas tenham acesso à internet, Sen (2010) coloca que uma das consequências da "diversidade humana" é que a igualdade tende a andar, num determinado espaço, de fato, junto com a desigualdade noutro. Portanto, ao se dar igualdade para um, tira-se do outro, não tem como todas as pessoas conseguirem a igualdade ao mesmo tempo e num mesmo propósito. Mas, no discurso das políticas públicas de inclusão digital, promete-se democratização no acesso à informação, prestação de serviços eficiente aos cidadãos, o que, na realidade, não acontece dessa forma.

De acordo com a Política de Governo Eletrônica, a inclusão digital deve se configurar como uma política universal, ou seja, como direito de cidadania. Mas alguns obstáculos, como a falta de investimentos essenciais para se desenvolver uma política pública de inclusão digital, bloqueiam sua realização, embora muito se tenha feito para dar oportunidades de acesso, como os telecentros, nas comunidades mais carentes, conexão via satélite, cidades digitais, softwares livres, entre outros.

Pesquisas realizadas pelo Comitê Gestor de Internet no Brasil (AFONSO, 2006) e outras entidades mostram pontos de necessidade, com estratégias políticas governa- 
mentais para unir e democratizar benefícios das novas tecnologias, pois:

1. Mais de 2.400 municípios, onde só há telefonia fixa, estão descartados pelas empresas privadas de telecomunicações e de serviços internet.

2. A conectividade é nula ou muito precária em quase todas as nossas áreas rurais.

3. Milhares de bairros das cidades maiores também estão abandonados, por razões de mercado, pelas concessionárias, onde não há nenhum serviço de "banda larga".

4. Há mais de 33 milhões de crianças na escola fundamental e cerca de 10 miIhões no ensino médio, em cerca de 160 mil escolas públicas.

5. Mais de $50 \%$ das famílias brasileiras vivem com menos de dois salários mínimos por mês.

A nova realidade da globalização criou um modelo de desenvolvimento industrial fundado na inovação científica e tecnológica, caracterizando o capitalismo e distanciando o acesso às TIC's para a população de baixa renda. Como aborda Proenza (2003), o próprio desenvolvimento das TIC's, ocorrido sob o processo de globalização atual, tende também a criar novos elementos que contribuem para ampliar as desigualdades econômicas.

Estes apontamentos servem para repensar as estratégias de governo nas políticas públicas, a fim de que possam atender a população na acessibilidade às tecnologias digitais, com ações que beneficiem realidades diferentes, atendendo as demandas e ampliando a conectividade no país.

\section{Políticas Públicas de Inclusão Digital na Educação}

A inclusão das tecnologias nas escolas surge como uma questão crucial nos novos padrões de desenvolvimento das TIC's, tanto para a inserção social, por meio das redes, como para o manuseio na aprendizagem escolar, estendendo-se à vida familiar dos alunos.

Nos moldes dos Parâmetros Curriculares Nacionais - PCN (BRASIL, 1996), a necessidade de um ensino de qualidade exige uma prática educativa que atenda às necessidades deste cenário inovador, onde se torna imprescindível:

[...] propor uma prática educativa adequada às necessidades sociais, políticas, econômicas e culturais da realidade brasileira, que considere os interesses e as motivações dos alunos e garanta as aprendizagens essenciais para a formação de cidadãos autônomos, críticos e participativos, capazes de atuar com competência, dignidade e responsabilidade na sociedade em que vivem (BRASIL, 1996).

As crises econômicas, no nosso país, dificultaram investimentos para a educação, principalmente na educação formal ${ }^{4}$. $\mathrm{O}$ alto grau de desigualdade na educação formal

\footnotetext{
${ }^{4}$ Educação formal é aquela que se obtém nas escolas oficiais (públicas ou particulares), cujos cursos são reconhecidos pelo MEC e comprovados através de certificados e diplomas igualmente registráveis no Ministério da Educação e Cultura.
} 
diferencia o uso das potencialidades oferecidas pelas TIC's.

Para que o Brasil pudesse reverter esta situação e competir com o mercado mundial, foi lançado o Livro Verde do Programa Sociedade da Informação no Brasil, em 2000, com o propósito de universalizar o acesso às TIC's e promover a alfabetização digital (BRASIL, 2000). Pode-se considerar uma ação social válida, mas também tem que se avaliar o quanto tais abordagens contribuem para que a população possa articular suas ações através das tecnologias e gerar transformações sociais, educacionais, culturais e econômicas.

Nesse contexto, é notável a discussão do papel da educação como escola, num viés amplo, que contemple os conteúdos, a aprendizagem colaborativa, autorias e coautorias, e não apenas o uso no mercado de trabalho, numa abordagem superficial e ligada aos interesses econômicos. Partindo desse pressuposto, o Governo Federal ${ }^{5}$ iniciou projetos governamentais na perspectiva de promover a inclusão digital nas escolas públicas, a fim de contemplar os alunos de baixa renda e principalmente os da periferia com o acesso às tecnologias, ofertando banda larga, computadores e tablets, além de laboratórios de informática às escolas.

Mas este aparato nas escolas públicas não é o suficiente para integrar os alunos às novas tecnologias e, consequentemente, capacitá-los a atuar na sociedade de informação. Morin (2011) destaca que hoje vivemos numa época de mundialização, todos os nossos grandes problemas deixaram de ser particulares para se tomar mundiais. Seguindo a idéia do autor, o problema da inclusão digital é que ela não está envolvendo todas as pessoas que fazem parte da sociedade, é preciso pensar no todo, quando se refere às políticas públicas de inclusão digital na educação, para depois analisar as partes, incluindo as ações de sua implantação nas escolas públicas.

Dessa forma, não basta oferecer acesso às TIC's através da escola, há a necessidade da democratização no uso e na formação dos sujeitos sociais. Algumas escolas estão disponibilizando o acesso aos laboratórios de informática à comunidade, tentando constituir um espaço estratégico de promoção da inclusão digital. Quando o governo promove o uso do laptop aos alunos da escola pública, para que o levem para casa e a família tenha acesso a essa tecnologia, esquece-se de que a conexão com a internet não está disponibilizada para todos, e aí não ocorre a vivência plena da cultura digital, porque navegar na rede significa estar em contato com o mundo, comunicando e obtendo informações.

Por mais que o Governo Federal, através do MEC, promova ações nesse sentido, ainda são incipientes.

\footnotetext{
${ }^{5}$ Programa Nacional de Tecnologia Educacional (Prolnfo) - É um programa educacional com o objetivo de promover o uso pedagógico da informática na rede pública de educação básica. Projeto Um Computador por Aluno (UCA) - uma iniciativa do Governo Federal - foi implantado com o objetivo de intensificar as tecnologias da informação e da comunicação (TIC) nas escolas, por meio da distribuição de computadores portáteis aos alunos da rede pública de ensino. Programa Banda Larga nas Escolas (PBLE) foi lançado no dia 4 de abril de 2008 pelo governo federal, por meio do Decreto $n^{\circ} 6424$ que altera o Plano Geral de Metas para a Universalização do Serviço Telefônico Fixo Comutado Prestado no Regime Público (PGMU). O uso de tablets no ensino público é outra ação do Proinfo Integrado, programa de formação voltada para o uso didático-pedagógico das Tecnologias da Informação e Comunicação (TICs) no cotidiano escolar, articulado à distribuição dos equipamentos tecnológicos nas escolas e à oferta de conteúdos e recursos multimídia e digitais (BRASIL, 2013).
} 
Hoje o que se tem de acesso real na tecnologia digital é o Programa Nacional de Tecnologia Educacional (Prolnfo), criado em 1997, com o objetivo de contribuir com a inclusão digital por meio da ampliação do acesso a computadores, da conexão à rede mundial de computadores e de outras tecnologias digitais, beneficiando a comunidade escolar e a população próxima às escolas, com laboratórios equipados com computadores, rede de internet banda larga e impressora, não apenas para auxiliar os alunos na pesquisa, e sim, de acordo com Oliveira (1997), servir como ferramenta auxiliar do processo ensino-aprendizagem. Nessa perspectiva, o governo preocupou-se em capacitar professores para atuarem com os computadores, de forma atrativa e interativa, para os alunos. Nos gráficos abaixo, tem-se um panorama da implantação do Prolnfo nas escolas públicas do país.

\section{Gráfico 1 - Panorama da implantação do Prolnfo nas escolas públicas do país}

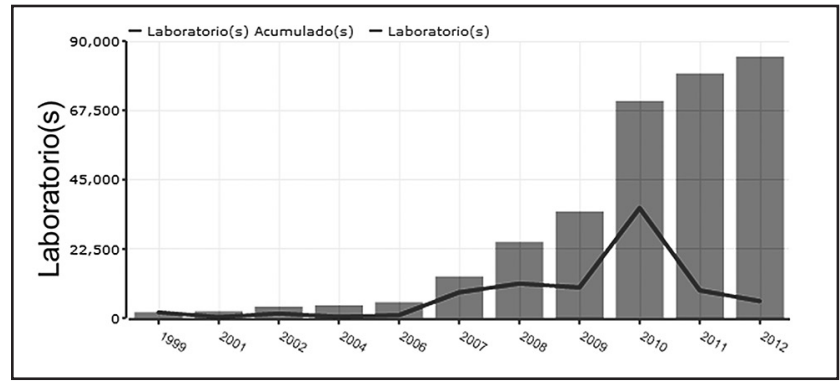

Fonte: Brasil (2013).

Gráfico 2 - Banda larga: número de escolas conectadas à internet

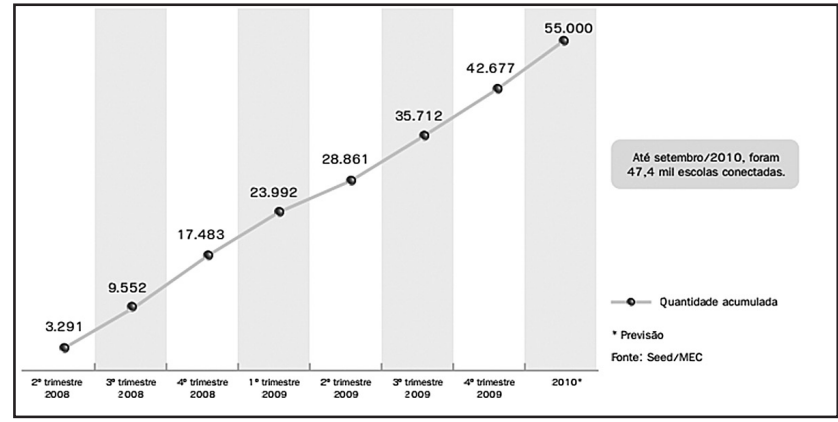

Fonte: Brasil (2013).

Apesar de alguns entraves na implantação das políticas públicas de inclusão digital na educação, pode-se considerar que se está no caminho da universalização do acesso à internet e às tecnologias digitais, tanto na zona urbana como na zona rural. 


\section{Inclusão digital na prática pedagógica do professor}

A sala de aula é um espaço importante para os alunos, pois é nela que se ampliam as possibilidades de ensino e aprendizagem. Para que esse processo aconteça, o educador deve ser o primeiro a estar adequado nesta sala de aula, para ser o mediador da aprendizagem dos seus alunos, ativo, para desenvolver-lhes a criticidade e a curiosidade.

A existência das tecnologias digitais influenciou também a prática pedagógica do professor, porque, tendo essas ferramentas, ele precisa conciliá-las com o conteúdo, planejando aulas mais otimizadas, mas com um problema: como utilizar a tecnologia na complementação das aulas. Ao introduzir as tecnologias na sala de aula, o professor está desafiando a sua práxis, numa mudança de paradigma que compõe a nova sociedade do conhecimento.

Para Perrenoud (2000), as tecnologias, como um auxílio ao ensino, devem servir para mudar o paradigma e concentrar-se na criação, na gestão e na regulação de situações de aprendizagem. Nessa perspectiva, o ofício do professor trata-se de "fazer aprender". É preciso substituir a pedagogia rígida e tradicional por uma pedagogia que desenvolva competências como aprender a buscar informações para compreendê-las e saber utilizá-las na resolução de problemas.

Com relação a mudanças, principalmente no modo de pensar e agir, Morin (2011) explica que a complexidade coincide com uma parte da incerteza, seja ela proveniente dos limites de nosso entendimento, seja inscrita nos fenômenos. O professor não está preparado para enfrentar situações que envolvam uma transformação na sua prática pedagógica, a qual está enraizada nos moldes da educação analógica; portanto, apresenta-se inseguro, resistente e indiferente às novas tecnologias.

Pensar em inserir tecnologias e mídias à organização de atividades educacionais requer reestruturar a forma de planejar a ação didática. Além da inserção dos recursos, há que se pensar um contexto em que elas se façam significativas e que envolvam todos os sujeitos do processo na ação de aprender. Conforme Moran (2013), ainda não existe um modelo de pedagogia inovadora com as tecnologias na escola, devido a ranços na formação docente, pois, ainda,

[...] no planejamento didático, predomina uma organização fechada e rígida, quando o professor trabalha com esquemas, aulas expositivas, apostilas, avaliação tradicional. O professor que 'dá tudo mastigado' para o aluno, de um lado, facilita a compreensão; mas, por outro, transfere para o aluno, como um pacote pronto, o conhecimento de mundo que ele tem (MORAN, 2013).

Diante da necessidade de o professor rever o seu papel de educador como problematizador, é importante pensarmos em como isso tem sido suscitado nas escolas e se esses professores têm tido a oportunidade de repensar a própria prática e aprimorar seus conhecimentos sobre as contribuições das tecnologias na educação. No que diz respeito ao preparo dos professores, para que utilizem as novas tecnologias computacionais, encontramos cursos de capacitação e de treinamento baseados em diferentes enfoques, metodologias e objetivos. Valente (1999) nos apresenta algumas abordagens de capacitação de professores para o uso da informática educativa: 
- Treinar o professor para o uso das tecnologias, oferecendo curso fora do ambiente de trabalho. Os conteúdos e atividades desenvolvidas são propostas independentemente da situação física e pedagógica existente na escola onde os professores atuam. Aplicar conhecimentos recém adquiridos não é algo que acontece de imediato, requer experimentação e diálogo com outros colegas.

- Levar um curso para dentro da sala de aula, para Valente (1999), é uma proposta difícil, mas muito interessante. Neste caso, é preciso um professor formador presente na escola, trabalhando com base no compartilhamento de experiências com os professores das salas de aula. Por serem presenciais, esses cursos podem acarretar problemas de operacionalização, uma vez que há dificuldade para garantir que o professor formador esteja na escola sempre que necessário, assessorando os demais professores.

Valente (1999) ainda afirma que a formação do professor, para que seja capaz de integrar a informática em suas atividades pedagógicas, deve oportunizar a construção de conhecimento sobre as técnicas computacionais, criando também condições para que o professor recontextualize o aprendizado e a experiência vivida no seu cotidiano escolar, compatibilizando as necessidades de seus alunos e os objetivos pedagógicos que se dispõe a atingir.

Uma das ações do Governo Federal é o Projeto Computador Portátil para Professores (BRASIL, 2008), no intuito de aproximá-los das tecnologias digitais, com o objetivo de propiciar um ambiente favorável à inovação na área de educação, paralelamente ao desenvolvimento de futuras tecnologias, nas áreas pedagógica e social, contribuindo, assim, para a melhoria da qualidade do ensino público brasileiro. Considera-se importante essa ferramenta nas mãos do professor, pois o acesso pode acontecer em qualquer lugar, mas o educador precisa conhecer e saber usar o computador, desenvolvendo uma formação intelectual e pedagógica.

Dessa maneira, foi criado o Programa de Formação Continuada em Tecnologia Educacional (Prolnfo Integrado) ${ }^{6}$, ofertando os seguintes cursos: Introdução à Tecnologia Digital, Tecnologias na Educação, Elaboração de Projetos e Redes de Aprendizagem (BRASIL, 2013), que pode ser ilustrado pelo Gráfico 3.

\footnotetext{
${ }^{6}$ O ProInfo Integrado é um programa de formação voltada para o uso didático-pedagógico das Tecnologias da Informação e Comunicação (TICS) no cotidiano escolar, articulado à distribuição dos equipamentos tecnológicos nas escolas e à oferta de conteúdos e recursos multimídia e digitais oferecidos pelo Portal do Professor, pela TV Escola e DVD Escola, pelo Domínio Público e pelo Banco Internacional de Objetos Educacionais.
} 
Gráfico 3 - Professores e gestores capacitados pelo Proinfo

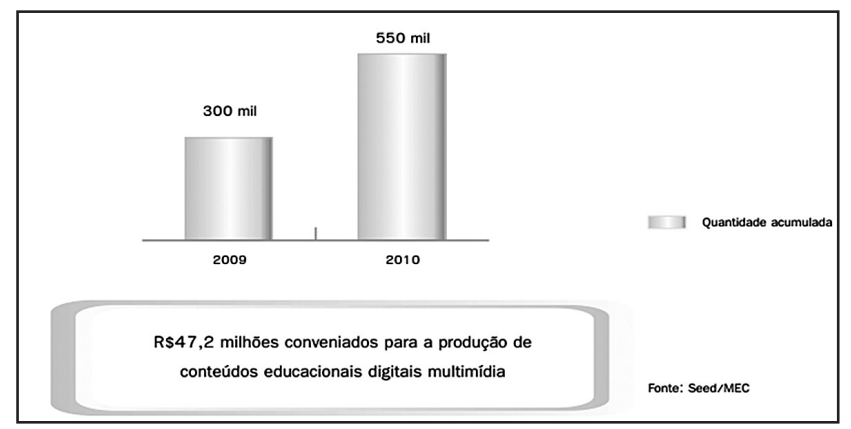

Fonte: Brasil (2013).

Essas capacitações vêm ao encontro das necessidades de haver nas escolas professores capazes de utilizar as tecnologias digitais como suporte pedagógico que internaliza os conteúdos das aulas de forma interativa, moderna e colaborativa, o que Leff (2010) assinala como relações entre o conhecimento teórico e os saberes práticos, acelerados pelo advento do capitalismo e o surgimento da ciência moderna.

\section{Sociedade contemporânea x Sociedade da informação}

As mudanças e transformações acompanham a evolução da sociedade, caracterizando novos modos de ser e viver do ser humano, é o progresso que, na afirmação de Heidemann (2009), é uma condição necessária para que as pessoas comuns possam superar seu destino de danação social.

Na sociedade contemporânea, uma das características fundamentais para o processo de produção é o conhecimento presente no novo paradigma econômico, voltado para o uso do conhecimento e da informação a fim de atender as exigências do mercado, integrando um novo capital.

O conhecimento encontra-se num emaranhado de informações constantes, numa rapidez sem igual, e, para ser disseminado, há a necessidade da globalização do conhecimento. Neste sentido, as Tecnologias de Informação e Comunicação - TIC's corroboram na ampliação dessas informações, que vão desde a escola até a sociedade. Como salienta Leff (2010), a tecnologia constitui-se no meio eficaz para a aplicação dos conhecimentos científicos à produção de mercadorias.

A revolução da informática, no viés da internet, possibilita novas interações sociais com a comunicação em redes sociais, o consumo virtual, enfim, uma nova expressão cultural. Apesar de toda essa tecnologia e praticidade, os desafios na sociedade da informação estão na racionalidade que está se formando neste cenário, que não consegue resolver os problemas sociais.

Existe um paralelo entre tecnologia, modernidade e desigualdade social; analfabetismo, miséria, desemprego. Dessa forma, o papel da tecnologia é de construir novos modos de conhecimento para se alcançar objetivos que proponham caminhos para minimizar esses problemas. 
Assim, o que se torna importante neste contexto é o processo de aprendizagem, não somente a oferecida pela escola, mas sim aquela que é constante e faz parte da nossa vida. Nessa nova sociedade, o aprender é um processo complexo, e a construção do conhecimento ocorre a partir da ação do indivíduo sobre a realidade. Para Morin (2011), ação é estratégia, e a estratégia luta contra o acaso e busca a informação.

\section{Considerações finais}

Vivemos numa sociedade do conhecimento pelo viés do capitalismo, com as informações presentes a todo instante através das TIC's. Esse momento da história, chamado de revolução da informática, não retrocede, ao contrário, amplia-se e exige a produção e a construção do conhecimento para atender a essa nova realidade.

Na organização dessa sociedade, surgem as políticas públicas de inclusão digital, possibilitando o acesso e a expansão das conexões em rede. A criação delas auxilia na sistematização das tecnologias, mas não o bastante para abranger toda a sociedade, ocasionando uma exclusão digital para uns e a inclusão digital para outros.

Na propagação das tecnologias digitais, surge a escola, com seu papel fundamental de oportunizar o seu acesso e uso aos alunos e professores, contemplando uma massa maior, que é a comunidade onde se insere. Dentro desse espaço, surgem os desafios de possuir as ferramentas tecnológicas, e não saber utilizá-las: o professor, despreparado para conceber o computador como ferramenta pedagógica na sua prática, e os alunos, tentando incluir sua família neste processo, mas sem condições, sem estrutura básica para tal fim.

Em suma, as tecnologias oferecem grande potencial de mudanças e desenvolvimento, que surgirão com as gerações futuras através da transformação das práticas políticas, educacionais e sociais.

\section{Referências}

AFONSO, Carlos A. Políticas Públicas e Inclusão Digital. In: CGI.br (Comitê Gestor da Internet no Brasil). Pesquisa sobre o uso das tecnologias da informação e da comunicação 2006. São Paulo, 2007. p. 47-53.

BERNHEIM, Carlos Tünnermann; CHAUÍ, Marilena Souza. Desafios da universidade na sociedade do conhecimento: cinco anos depois da conferência mundial sobre educação superior. Brasília: UNESCO, 2008.

BRASIL. Decreto no 6.504, de 4 de julho de 2008. Institui o Projeto Computador Portátil para Professores, no âmbito do Programa de Inclusão Digital, e dá outras providências. Disponível em: <http://www.planalto.gov.br/ccivil_03/_Ato2007-2010/2008/Decreto/ D6504.htm>. Acesso em: 14 jul. 2013.

. Fundo Nacional de Desenvolvimento da Educação. FNDE. Disponível em:

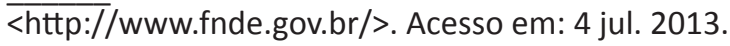


. Lei no 9.472, de 16 de julho de 1997. Lei Geral das Telecomunicações. Diário

Oficial [da] República Federativa do Brasil, Poder Legislativo, Brasília. Disponível em: http://www.planalto.gov.br/ccivil_03/leis/L9472.htm>. Acesso em: 14 jul. 2013.

. Ministério da Educação e Cultura. Secretaria de Educação a Distância. Programa Nacional de Informática na Educação. Brasília: Ministério da Educação e Cultura/Banco Interamericano de Desenvolvimento, 1996.

. Ministério da Ciência e Tecnologia. Sociedade da Informação no Brasil. Livro Verde. Brasília, 2000.

FREY, Klaus. Políticas Públicas: um debate conceitual e reflexões de Políticas públicas no Brasil. In: Planejamento e Políticas Públicas - PPP n. 21, jun. 2000. Disponível em: <www.ipea.gov.br/pub/ppp/ppp21/Parte5.pdf>. Acesso em: 14 jul. 2013.

HEIDEMANN, F. G. Do sonho do progresso às políticas de desenvolvimento.

In: Heidemann, F. G.;e SALM, J. F. (Orgs.). Políticas públicas e desenvolvimento: bases epistemológicas e modelos de análise. Brasília: UNB, 2009

HOBSBAWM, Eric. Era dos Extremos: o breve século XX. São Paulo: Companhia das Letras, 1995.

IBGE. Instituto Brasileiro de Geografia e Estatística. Pesquisa Nacional por Amostra de Domicílios. Diretoria de Pesquisas, Coordenação de Trabalho e Rendimento. Rio de Janeiro, 2005.

LASWELL, H. D. Politics: Who Gets What, When, How. Cleveland: Meridian Books, 1958.

LEFF, Enrique. Epistemologia ambiental. São Paulo: Cortez, 2010.

LYNN, L. E. Designing Public Policy: A Casebook on the Role of Policy Analysis. Santa Monica: Goodyear, 1980.

MORAN, José Manuel. Como utilizar as tecnologias na escola. Disponível em:

<http://www.eca.usp.br/prof/moran/utilizar.htm>. Acesso em: 4 jul. 2013.

MORIN, Edgar. Introdução ao Pensamento Complexo. Porto Alegre: Sulina, 2011.

NERI, Marcelo Côrtes. De Volta ao País do Futuro: crise europeia, projeções e a nova classe média. Rio de janeiro: Centro de Pesquisas Sociais/Fundação Getúlio Vargas, 2012.

OLIVEIRA, Ramon de. Informática Educativa. Campinas: Papirus, 1997.

PERRENOUD, Philippe. Dez novas competências para ensinar. Porto Alegre: Artes Médicas Sul, 2000.

PROENZA, F. e-Para Todos. In: SILVEIRA, S; CASINO, J. (Orgs.). Software Livre e Inclusão Digital. São Paulo: Conrad, 2003.

SEN, Amartya. Desenvolvimento como Liberdade. São Paulo: Companhia das Letras, 2010.

VALENTE, José Armando (Org.). O Computador na Sociedade do Conhecimento.

Campinas: UNICAMP/NIED, 1999. 